\title{
WHY DO WE MOOT? EXPLORING THE ROLE OF MOOTING IN LEGAL EDUCATION
}

\author{
ANDREW LYNCH*
}

\section{INTRODUCTION}

One of the most specialised pieces of assessment featured in a law degree is the moot. Most Law Schools have a mooting component in some form and at some level, yet given the sparseness of the literature on this topic, it seems that the presence and use of mooting is rarely called into question. The only apparent reasons for the existence of mooting programmes are tradition and the correlation to the realities of professional practice. But is this enough?

The overall purpose of this article is to provide valid educational and practical justifications for the exercise of mooting. This process begins by defining the essential characteristics of mooting, as it has existed over the centuries. This discussion will be given contemporary relevance by an examination of how three Queensland Law Schools currently feature moots in their undergraduate curriculum.

The three theoretical bases for mooting as a means of learning, which the paper explores are constructivism, experiential learning and problem-based learning. As such, mooting has a clear role to play in a law curriculum informed by such educational perspectives. There is also a general discussion on the place of moots in the student approaches to learning (SAL) framework.

Additionally, the paper seeks to reveal student reactions to mooting through qualitative research. It is not particularly beneficial to place moots in a theoretical context if there is little understanding of their practical effect. The data gathered from the focus group interviews conducted for this study supports many of the propositions made in the earlier section of the paper, where moots are viewed from the perspective of educational theory.

The final part of the paper seeks to take all of the above and make a statement about the value of moots as a form of assessment in the law curriculum. The purposes of assessment are discussed in conjunction with the theoretical views of mooting examined earlier in the paper, as well as the practical outcomes of mooting identified in the group interviews. The conclusion is reached that there are excellent practical and theoretical justifications for moots and by appreciating these reasons, law teachers can begin to better understand the strengths and benefits of this assessment tool.

\section{PART A: MOOTS IN PRACTICE}

\section{The Development and Characteristics of Mooting}

An obvious starting place is to attempt to define exactly the features of mooting. Any discussion of the educational merit of the practice cannot be meaningfully conducted without clarifying what is involved when we moot.

In engaging in this defining process, it is instructive to refer to the history of mooting. The practice of mooting is buried in early legal history. It is extremely difficult to pinpoint precisely when the practice came into usage, but the genesis of moots can be traced back to the establishment of the Inns of Court of medieval times. Young men ${ }^{2}$ residing at the Inns as apprentices took instruction from their seniors and were required to perform in moots over several years before they could be admitted as practitioners. Moots were 
one of the few formal features of the legal education of the time. ${ }^{3}$ There was "no prescribed attendance, no lectures and no regular course of study, a student being simply obliged to eat three dinners ... in the Hall of the Inn, in each of the four terms"4 for a number of years. The required attendance at meals was important as discussions of cases were held after dinner, and moots were conducted following supper. ${ }^{5}$

The section on barristers in Halsbury's Laws of England outlines the respective roles of the Inns members in moots. That they were the key component of early legal education is demonstrated by the following passages:

The senior members of the society formed the bench ...; the persons who argued at the bar of the Inn ... were called ... utter barristers, because they sat "uttermost" on the forms which constituted the bar... The members of the Inn who took part in these exercises and sat inside on the same form and merely recited the pleadings were [called] inner barristers, and were afterwards called students.

No member of an Inn of Court could have a chamber in his Inn, or be in commons, unless he kept moots ${ }^{6}$ within three years after his admission. After being "usually in commons", and "keeping the case" in hall, and performing satisfactorily in a number of moots in the house to which he belonged, and in one of the Inns of Chancery, the member, when of seven years' standing from admission, could be called to the utter Bar. After being so called he could not continue to keep his rank of utter barrister unless for three years after his call he participated in ordinary mootings and other ordinary exercises of learning ...7

This extract is illuminating for two reasons. Firstly, it shows how important moots were in educating the early practitioners ${ }^{8}$ before formalised university accreditation ${ }^{9}$ Mooting features at all stages of the apprentice's progression through his education and is the condition attached to that continued progression. Secondly, although the emphasis on mooting has clearly been reduced by the emergence of Law Schools, with their use of other forms of assessment, it seems that the practice has remained largely unaltered from this early model. Certainly the devices of the inner and utter bar have long been forgotten, but the essence of students presenting legal argument to a specially constituted bench of their superiors as part of their education is the same.

Today moots are still seen as asking "students to argue points of law before a simulated court". ${ }^{10}$ Many moot programs seem to follow the general pattern described so intricately by Gaubatz ${ }^{11}$ of requiring students to prepare and submit briefs, and deliver their case to a "fake" bench, which is always ready to interrupt with questions. This is confirmed by the current practice of mooting in today's Law Schools.

In summary, it seems that there are three key features of mooting which have remained from the Inns of Court and continue in practice today:

- students assume the roles of advocates before a simulated bench (which may comprise professionals and/or academics, or students - depending on the formality of the proceedings);

- students argue points of law before the bench, which arise from a hypothetical scenario they have been supplied with;

- students are expected to be able to answer questions from the bench relating to the arguments presented or any other relevant law that the students may not have considered.

These are the bare essentials of a moot. Of course, as evidenced by the survey of Queensland Law Schools, many programs operate on a much more sophisticated level than this and may require briefs to be submitted and other students to take the part of instructing solicitors. The exercise may occur in a real court, a moot court room or a classroom. It may be videotaped or it may not. These are all variants on the common theme, which is comprised of the stated elements above. They can enhance the experience for both students and assessors, but they do not alter the basic requirements of the exercise.

Le Brun and Johnstone distinguish moots from mock trials by stating that the latter seek to recreate the whole court experience, including witnesses and even juries. ${ }^{12}$ The distinction is a valid one and it should be noted that a moot does not involve the full trappings and features of a trial. ${ }^{13}$

It should also be noted that the term "moot" is often used to refer to activities which are conducted in a fairly relaxed manner in the classroom. ${ }^{14}$ Commonly this involves allocating the various roles of counsel and judge to students and having them argue the points of law during the class. Whilst this is clearly related to what occurred centuries ago at the Inns of Court, it differs from moots "proper" in that in most cases preparation time is extremely limited and much of the formality (and presumably the consequent student anxiety) is dispensed with. The varying degrees of formality in mooting are not of crucial significance to this paper. While most of the discussion relates to the context of formal assessable mooting, the comments 
and analysis of the practice of mooting and its advantages as an educational tool and item of assessment will apply generally.

\section{Current Use of Mooting in Three Queensland Law Schools ${ }^{15}$}

There are a variety of ways in which mooting can feature in an undergraduate law course. What this says about our understanding of moots is unclear, given that there are reasons other than educational ones which determine the structure of a curriculum. At the time of writing, all five Law Schools in Queensland have a mooting component though the amount of mooting and the stages of the curriculum at which it occurs differ greatly.

This section of the paper will examine the approach taken by three of the Queensland Law Schools those of Griffith University (Griffith), the Queensland University of Technology (QUT) and the University of Queensland (UQ). It should be stressed that the purpose of this exercise is not to display a preference for one institution's approach over another. These three universities have been chosen solely because of the contrast which they demonstrate. Their approach to mooting is determined by their own characteristics and objectives and the author does not seek to judge them by an external standard.

Griffith has compulsory moots in a number of subjects so that by the conclusion of fourth year, all students have performed at least five moots. Students are introduced to mooting in Week 13 of first semester in the first year subject Law and Legal Obligations, where they moot in teams of two, each speaker being allotted five minutes presentation time. This brief and informal introduction to mooting is built upon steadily over the next four years, with mooting time becoming longer and the pre-moot preparation more complex. There is no obligation for there to be a moot in every year and the structure of the moots is largely determined by the convenor of the subject in which it is featured. As a consequence, the moots are of varying formality and may require different things of the mooters depending on the individual convenor's approach.

By contrast, QUT moots are offered as an optional form of assessment in selected specific subjects in each year of the curriculum. This places restrictions on the number of students who may actually have the chance to moot in a year. The impact of this restriction is heightened by the greater numbers of students enrolled at QUT — presumably the reason why compulsory moots are not regarded as a feasible option.

The mooting process, once entered into, is highly structured and formalised. Regardless of the stage of the degree course at which the students moot, all mooters must comply with a single set of prescribed standards and rules which are published in the Faculty's Moot Guide. In addition to providing students with the assessment criteria, outlining the responsibilities of those acting as solicitors or barristers, legal research advice, and references for preparatory readings, the Moot Guide specifies the procedures which must be followed precisely by the mooters. This involves naming the times by which written submissions and lists of authorities must be presented, and a number of other steps which are set out in a "Schedule of Preliminary Steps for Mooters". Most moots are held at the Queensland Law Courts complex and the relevant academic is joined on the Bench by practising members of the profession, if not the judiciary. ${ }^{16}$

The UQ approach is different again. Unlike the previous two examples, moots at UQ are not attached to any specific subjects but rather are featured in particular advocacy subjects, which prepare students for, and then engage them in, mooting. These subjects are compulsory, with students being required to do two moots for their Bachelor of Laws degree in third and fourth year. These moots are conducted formally in the UQ moot court room in the presence of senior members of the legal profession. The cornerstone of the UQ programme is that if mooting is to replicate the realities of practice, then it should not deal with a fact scenario confined to a discrete legal area. ${ }^{17}$ This is a feature which can be contrasted with both Griffith and QUT. The emphasis is significantly different at UQ where the experience aims to develop students' research and advocacy skills, but is not seen as a means for students to learn a specific area of the substantive law. The UQ moots are devised on the basis of the interconnectedness of the many subjects which make up the degree, but at the other two universities they are seen as a tool for assessing distinct areas of the law.

From examining just three Law Schools of the many which now exist in Australia, it can be seen that there are several ways of approaching the incorporation of mooting in an undergraduate degree. However, it should be realised that it is not possible to criticise a law curriculum solely on the number of opportunities 
for mooting it gives students. Mooting involves a vast amount of administrative co-ordination ${ }^{18}$ as well as actual time spent assessing each individual student's oral (and, in some instances, written) submission and performance. In fact, mooting is perhaps the most time consuming activity which a legal academic can feature in a course and so the practical possibility of holding moots is limited more than is the case with most other forms of assessment, and is largely determined by staffing resources and student numbers. However, it is the view of the author that by examining the kind of learning which mooting seeks to (and actually does) foster, we may arrive at a clearer understanding of the role of mooting in the undergraduate law degree.

\section{PART B: MOOTS AND EDUCATIONAL THEORY}

\section{Moots and the Theories of Learning}

Moots involve students in many tasks and are a form of assessment which combines both substantive law and a range of skills. ${ }^{19}$ There are a variety of specific educational perspectives from which moots can be viewed. However, as a preliminary point, it is worthwhile to consider theories of student approaches to learning (SAL). It seems that moots are an extremely good example of assessment which involves a “multidimensional” approach by students.

Biggs $^{20}$ identifies the two meanings of the term "approaches to learning”. The first concentrates on the strategies ${ }^{21}$ and processes which students adopt and which "directly determines the outcome of learning” ie. a cognitive perspective. The second meaning focuses upon students' "predispositions to adopt particular processes". This view is concerned more with what Bloom labelled the affective domain. ${ }^{22}$ Therefore, in essence, students' approaches to learning can be viewed as motives (affective) and related strategies (cognitive):

Approaches in the SAL (student approaches to learning) framework, then, are multidimensional. They comprise several aspects in both motive and strategy components, and are only meaningful in context, being related to student intentions and to the existential teaching/learning context on the one hand, and to the quality of the learning outcome on the other. ${ }^{23}$

This view is in accord with that taken by Ramsden, explaining the work of Marton, when he wrote that there were two aspects to a student's approach to learning - the How (or structural) aspect and the What (or meaning) aspect. ${ }^{24}$ The What aspect is concerned with students' motivations and affective responses, whilst the How aspect focuses on organisation and planning. However, he also concludes that:

[i]n practice, these two aspects of approaches are fused together. In order to understand, a student must integrate and organise and see the text or other learning task as a whole. It makes no sense to talk about the meaning attributed to something unless one also talks about how the meaning is constituted. On the other hand, how a student structures a task cannot be considered in isolation from what he or she is intending to structure. ${ }^{25}$

Moots reflect this "equilibrium between cognitive and affective factors". ${ }^{26}$ The replication of the adversarial system requires each side to formulate a plan of attack or strategy. This is consciously done and will involve predicting arguments of the opponents and how they may be countered. ${ }^{27}$ Additionally the topic must be defined, researched, and then often divided between team members.

Thus the SAL framework also includes both motivational and affective aspects of students' learning. The exact nature of students' affective responses to mooting will be explored later using the qualitative data, but it should be noted at this stage, that it is strong - probably stronger than is the case with many other pieces of assessment in legal education. This is due primarily to the extreme feelings of confidence and fear which mooting engenders and which "will influence both their [students'] beliefs about the value of strategies and their strategy selection”28 at the planning stage.

It is acknowledged that most things we experience - through formal education or otherwise, involve a combination of pure thought impacting with personal characteristics. However, moots are a perfect example of assessment in law which involves high degrees of cognition and metacognition in an affectively charged context. Students are thus expected to cope and respond on a variety of levels.

The above is an extremely general overview of the theory behind students' approaches to learning. Many of the concepts raised then and in the remainder of this section of the paper will be further explored in reference to the qualitative research. They are concepts which underlie the three ensuing perspectives 
from which moots may be viewed. These may not be the only perspectives, however, they do integrate well with each other to provide a clear picture of moots as a form of learning which may be constructivist, experiential and problem-based.

\section{Constructivism}

Constructivism is a very broad theory of learning which underlies many varied educational perspectives ${ }^{29}$ - including those of experiential learning and problem-based learning. The theory is simple in that it merely proposes that the learner is the prime focus of the educational experience and $\mathrm{s} / \mathrm{he}$ constructs their own knowledge. The teacher is not an omnipotent being capable of transferring knowledge to the student. ${ }^{30}$ The constructivist view owes much to the work of Säljö ${ }^{31}$ who identified six different conceptions of learning, the fourth and fifth of which are, respectively, learning as the abstraction of meaning and learning as an interpretative process aimed at understanding reality.

That these conceptions form the basis of a constructivist view of learning is apparent when Säljö states that they emphasise an "assumption that knowledge is construed by individuals as a result of an active effort on the part of the learner to abstract meaning from a discourse and also to relate this meaning to an outside reality. ${ }^{32}$

From the author's observations and experiences, as well as the responses of the twenty people interviewed, it is impossible to moot successfully without interpreting and abstracting meaning from the vast amounts of case and statute law (let alone academic writings) relevant to the moot problem. Moots involve memorisation and the retention of knowledge, but first the mooters must construct that knowledge from the materials they will discover through their research.

A point that needs to be made here is a reminder that the type of moot being envisaged is one which does not substantially involve students reviewing material they have gleaned elsewhere, be it lectures or set readings. Of course, moots may be revisionary in nature, depending on the objectives of the examiner, yet often they expose students to areas with which they are unfamiliar, or at least require a much deeper understanding than was necessary when the students were first introduced to the material. It is moots which share the latter feature that this discussion is relevant to.

Resnick, in discussing her view of "current cognitive theory" emphasises a constructivist approach:

First, there is a process of knowledge construction, not of knowledge recording or absorption. Second, learning is knowledge-dependent; people use current knowledge to construct new knowledge. Third, learning is highly tuned to the situation in which it takes place. ${ }^{33}$

These three characteristics of constructivism are all present in the case of moots. The third point which Resnick makes requires further explanation which the preceding two do not. Situated learning is often proposed as a means of overcoming the all too common phenomenon of students who "can describe and discuss various rules of law but are unable to apply this knowledge in a different context, particularly in a practical sense" ${ }^{34}$ Brown et al advocate engaging students in learning through the "ordinary practices of the culture" ${ }^{35}$ There can be no more obvious example of this in legal education than mooting. Whilst advocacy is only one dimension of a lawyer's existence, mooting can involve more "practices of the culture" than just oral court presentation. Legal research, formation of a case plan, writing of briefs, and, of course, problem solving, are all skills which are relevant to practice ${ }^{36}$ and are features of moots.

\section{Experiential Learning and Problem-based Learning}

Related to the notion that students construct their knowledge, is the idea that they do so by reflecting upon their experiences in a manner illustrated clearly by Kolb’s Experiential Cycle. ${ }^{37}$ The significantly reduced role of the teacher indicates the constructivist nature of the learning which the student engages in. There is little imparting of knowledge from teacher to pupil, but rather the student learns by a process of construction based upon experience and reflection.

It is clear that the "experience" from which students learn may be varied in nature, and can range from the humble lecture to actual work experience. ${ }^{38}$ Obviously, the degree of concreteness varies along this spectrum of possible experiences, however, the next best thing after real world experience are role plays into which category moots clearly fall. ${ }^{39}$ 
The relationship between experiential learning and other more general educational theories is well illustrated by the recent work of Andresen, Boud and Cohen ${ }^{40}$ who state that a key feature of experiential learning is that it involves the "whole person — intellect, feelings and senses", or in the terms used earlier in this paper, the cognitive and affective domains operate together. It was stated that this seemed to be a strong feature of moots, and the reason for this would seem to be that it is a key characteristic of experiential learning. Additionally, Andresen et al acknowledge that experiential learning "supports a more participative, learner-centred approach, which places an emphasis on personal experience, rich learning events and the construction of meaning by learners. ${ }^{41}$

This clearly relates to the discussion of constructivism and the student's role at the centre of his or her own learning. By engaging in the experiential learning cycle, students are working within a framework to construct their own knowledge.

Another advantage of mooting is that it is readily applicable to problem-based learning (or PBL). Though this originated in reference to the teaching of medicine, it has found supporters in many disciplines, including law. In essence, Winsor explained PBL when he wrote:

this form of LEARNING (as distinct from TEACHING) is based on your tackling a problem, or series of problems, without prior instruction. The idea is to get you to indulge in what is described as 'discovery learning' by using your own initiative, but guided and assisted (rather than lectured or taught) by your instructor. ${ }^{42}$

In true PBL the process is both the focus for the problem and the assessment. Cowdroy comments on the suitability of this approach when he states that it is "particularly relevant where multiple alternative approaches and solutions can be applied to a generic problem, as is the case in advanced levels of architectural, legal and medical education, where multiple approaches and multiple solutions can be acceptable, but where the way of thinking about approaches and solutions is common."43

It is submitted that moots are a good example of a piece of assessment in legal education where the importance of the process applied in responding to the problem is at least equal to, if not more than, the emphasis on the actual solution reached. Mooters are not marked solely upon the accuracy of the law they argue in the moot court. Many of the arguments heard in moots are rather desperate, and the assessing academic knows this - has foreseen it in fact, when she or he drafted the question. The true test is to see how the students use the authorities that do exist in support of their argument, how they organise this material both individually and as a team, how they research the problem, and how they present it and respond to questions from the Bench. Certainly students are marked on their understanding of the law, but by the nature of the exercise, they cannot all reach the correct solution. The final answer to the problem posed by the case really plays a very minor role in both their learning experience and also the assessment of their work.

The work of Laurillard on discovery learning supports the view that students are more excited about figuring out the law from scratch and making the decisions as to what law is relevant so that the product is much more a result of their own reasoning and planning, than work which is informed and shaped by the teacher's treatment of the area in class. ${ }^{44}$ Students are capable of adopting deep or surface learning approaches depending on the nature of the task before them and what is required to complete it successfully. ${ }^{45}$ However, she recognises that discovery learning, which is similar in many ways to PBL, “invites a deep approach because it makes the problem the student's own problem". ${ }^{46}$ She makes it very clear that the key to this form of student learning is a high level of motivation as a result of students' increased role in the process. This appreciation of PBL has strong links with the general principles discussed above in regard to student approaches to learning. The quality of students' learning will be improved if we can motivate them by giving them more control over it. ${ }^{47}$

The traditional use of PBL in groups helps students learn communication skills and the necessity of cooperation. It also provides students with a support system, which can give valuable feedback. ${ }^{48}$ This advantage will be discussed in the third part of this paper. Clearly moots do involve a high degree of group work and peer learning and evaluation.

In conclusion, it is submitted that moots can fit easily within the PBL model and accord with the constructivist school of thought. Not only do they situate learning within a real-life practical experience, but they do so by requiring students to construct their knowledge from a problem within that context. Whilst the strength of this approach depends on the actual design of the moot program involved, the clear potential 
exists, and is made use of in many law schools, for moots to be a student-centred, problem-based learning experience.

\section{Integration of the Theoretical Perspectives}

In summary, this part of the paper has considered mooting from a number of educational viewpoints. It should be stressed that moots can reflect all of these theories at once. The examination of SAL literature is of general application to assessment items and is particularly apparent when students are mooting. The remainder of the theoretical section of the paper discussed constructivism as a broad school of thought and then focussed on two examples of it - experiential learning and PBL. Although these areas are often dealt with in isolation from each other for the purposes of analysis and discussion (as occurred here), in practice they may and often do, operate conjunctively. It is submitted that this is certainly the case with moots.

\section{PART C: THE REALITY OF MOOTING FOR STUDENTS}

\section{Research Methodology}

This part of the paper seeks to move from the educationalist's perspective and examine the experiences of students. In order to do this, qualitative data was collected through a number of focus group interviews. As the aim of the research was to have students describe the "salient behaviours, events, beliefs, attitudes, structures, and processes occurring in this phenomenon" ${ }^{49}$ it was decided that the method adopted should be designed to elicit qualitative responses. Quinn Patton favours qualitative methods, in preference to structured, statistical quantitative research, because they "permit the evaluator to study selected issues in depth and detail. Approaching fieldwork without being constrained by predetermined categories of analysis contributes to the depth, openness and detail of qualitative inquiry." 50

Tesch explains the essential distinction between quantitative and qualitative research as moving "away from numbers and back to asking people questions and to observing." ${ }^{51}$ Consequently, in-depth interviews are a long-recognised method in this kind of research, and the use of focus group interviews is well documented. ${ }^{52}$

The research is phenomenographical in nature, in that the aim is to describe students' experiences of mooting, rather than the exercise of mooting per se. As the founder of phenomenography stated: "we are not making statements about the world as such, but about people's thoughts about it." 53

Tesch describes phenomenography as research which seeks to discover patterns in people's conceptualization of a phenomenon which they experience..$^{54}$ By engaging in this form of research we can construct a clearer picture of the effect of mooting on our students.

Four groups of five students each were interviewed for this study. All participants are students enrolled in Law at Griffith University and were invited to participate so as to form groups containing students with a range of different marks for their moot work. Two groups were comprised of first year students, with third year students making up the other groups. This was done to determine whether there was consistency in the data gathered despite the differing levels of experience of the students. Additionally, the students were segregated on the basis of their gender. This is an approach which Russell recommends in the formation of synergetic focus groups ${ }^{55}$ on the basis that men and women behave differently in single sex groups than they do in mixed company. ${ }^{56}$ Regardless, several of the students interviewed stated that they felt more comfortable in groups of their own sex and the results of the research did not differ markedly between groups, but the way the different sexes approached the questions did, with the female participants being much more direct and open in discussing the emotions a mooter experiences.

The interviews were of roughly 45 minutes duration each. The planned questions were as few as possible so that the interviewees controlled the direction of the discussion. They were the following:

- Generally, what have been your experiences of mooting? What was it like?

- What are the features of that experience? What is it made up of?

- Can you give a judgement on the experience? Is it something you would or would not like to repeat, and why?

The researcher only asked questions additional to the ones above in order to clarify a point or to ask 
students if there were any other features they could identify, if they began to lose sight of the initial question.

The tapes of the four group interviews were typed by an independent third party and it was these transcripts which were analysed by the researcher. Phenomenographical analysis involves the researcher examining the data and selecting quotes which are illustrative in some way Groups of like quotes from across all the transcripts are formed and "eventually the meanings of each group begin to consolidate and to constitute a definite category". ${ }^{57}$ The aim of forming these "categories of description”, as they are known, is to "give summary descriptions of parts of data corresponding to conceptions of phenomena ... [T] he categories are not general characteristics of the conceptions but forms of expressing the conceptions." 58 In all, four categories of description arose from the focus group interviews which aid our understanding of the mooting experience.

\section{The Results: The “Categories of Description” of Mooting}

\section{Mooting prepares students for the "real world" through the acquisition of various skills}

It will be noted that the title of this first category is very broad. It was very tempting to substitute the phrase "professional practice" where "real world" currently appears, but to do so would involve a narrow reading of the comments of many of the students who felt that the real benefit in mooting was in its fostering of life-long skills which would be of use in that "real world" which is often perceived to exist in isolation from universities.

The most basic level of response from students just focussed on the fact that they had the chance to do something with their knowledge. That in itself was perceived as advantageous:

It was good to go through all the cases and take out what we have been learning theory wise and put it to a practical sense, because we go through and learn all these rules and principles but we don't actually get up and apply them to a situation which is something practical.

Slightly more sophisticated than this was the view that mooting:

gives you an indication of what you perceive you want to do with advocacy later on in life. If you would like to be a barrister at least you can see if this is what is supposed to happen, sort of thing, instead of it just being bookwork;

or:

getting back to where the relevance of them are - I don't know how they are compared to everyday court, because I don't spend enough time in court but I think because you are going to be there eventually it's going to be relevant can't understand how it couldn't be.

However, all participants placed greater emphasis on the general skills of relevance to the "real world" rather than the preparation to become lawyers. ${ }^{59}$ This was borne out by many remarks but the following are fairly indicative:

- And really the actual presentation of the moot is such a small part of it in comparison to the negotiation, the talking with your other colleagues and the communication of ideas and just creating and developing an argument;

- It's a great communication tool. It's a way of learning how to communicate in every field. I think it's very important to be able to build that confidence. That's the main problem — people don't have in general the confidence of speech in a group, you know, or with other individuals and the mooting gives you the opportunity to increase your argumentative abilities, which I think is very important as a source ... I mean as a professional you are going to end up doing something that involves you in arguing with somebody at some stage, so it is probably ... so it's fairly important;

- Research I think. Yes, as I said before, I think I learned more having done a moot than I would have just doing any other assignment. For me doing moots - it was the first time I had opened a case book. Now I don't feel intimidated by the library for my other subjects, I open the case books now;

- One other thing for me - the spinoffs that moots have for me is to - in other areas of my life — to be able to put forward a more cogent argument and actually take on an adversarial person whereas perhaps previous to doing moots or just the law degree generally (but I think moots have been a major influence), I usually try to find a sideline, try to find a compromise or way or back off. Having been forced into the 
position of adversarial combat then you are more comfortable when someone takes you on to respond in kind without losing your cool and maintaining a reasoned stance and so forth. So it's kind of empowering in that respect which is good.

It could be inferred from the data that these skills of which the students spoke are being acquired through their experience of mooting in accordance with Kolb's Experiential Cycle of Learning, but one student actually spelt it out by saying:

But it's excellent to learn from experience, I mean the more moots you do the better you are and you're always learning which is terrific.

In conclusion, it can be seen that law students value mooting for the practical dimension it adds to their education. The skills they glean from this experience are clearly adversarial and related to lawyering, but that is not seen as their prime focus. The phrases "communication skills" and "the skill of thinking on your feet" occur over and over in the transcripts. It seems mooting builds the law student as a person and prepares them for that "real world" in a way that other forms of assessment do not. This is particularly apparent in regard to the next category of description — teamwork.

\section{Mooting provides an opportunity for students to learn from their peers and develop group skills}

Although this is related to the first theme or description identified above, its prominence in the transcripts (and thus the experience of the students) warrants it a special place in the construction of what mooting actually involves. In an interesting piece actually concerned with PBL in aviation studies, ${ }^{60}$ the development of team skills in response to a teaching (or in the case of moots, learning) approach based upon groupwork are well documented. From the research conducted for the purposes of this paper, it appears that many students are aware of the chance to build relationship skills which mooting gives them.

The first year students, having done only one moot, did not have as many "horror stories" to recount on the mismatch of personalities that can occur in the allocation of mooting partners as did the more experienced students in third year. However, all students were agreed that moots provided the potential for meaningful groupwork which did not exist elsewhere in the course. Typical comments were as follows:

- I particularly liked that part of it. I thought it was really good because you had someone to bounce your ideas off and they say "no, that's wrong" and you fix it up. It is good like that;

- It goes way beyond just speaking in front of people. It builds up not just your skill of communicating to a wide audience, but really just communicating on a one to one basis with your partner;

- I would say that group work in moots is really quite unique mainly because when I do an assignment with group work in Commerce I can really separate the work and if you don't do all the assignment it doesn't matter because you are going to get all the marks and it doesn't matter. But in a moot you've got to stand up, the other person has to stand up, has to say something and so that can bring on such an intense pressure because you are relying on that person even more so because they are going to be seen, they are going to be heard. And for instance, if you like working to the deadline and like doing things under pressure, you work best that way, some of us do, and another person likes to have it done a week earlier, that can cause some conflict - yes, if your working styles are so different.

This last extract raises the issue of conflict within the group and how that experience translates for the mooters. Despite a few personal grudges, that whole aspect is still viewed as an advantageous experience:

... in most situations we have had to work with other people so it's meant that you have developed an ability to work as a team in some respects or you've learned how to survive as an individual in what's supposed to be a team situation that doesn't click, doesn't work for one reason or another, either people aren't interested or you can't seem to get together or you don't agree on the exact line you are going to take, so you split the arguments up and pretty much go your own way and come together in time for the moot. So I guess it helps you develop either team skills or coping skills.

This positive and philosophical attitude which many students adopt in regard to the teamwork aspect of mooting is demonstrated beyond doubt in the following extract which was the response of one student after another had suggested that mooters should be able to select their partners because "we want the best result [so] let’s get placed with somebody we know will help us achieve those results":

Results are part of the problem where the results are less important than the learning part of it. ${ }^{61} \mathrm{I}$ think being thrown in with somebody you don't know is fairly likely to happen later on in the future anyway. Being involved in 
a case or something like that, depending on what avenue you are working through, you might end up working with someone you don't know from a job previously and just be stuck with them and I think just being flexible is fairly important.

In conclusion, it can be stated that students are aware of and actually appreciate the benefits of teamwork that mooting can offer. Despite the chance that the moot planning reaches an impasse due to "terminal differences", all students were agreed that it was a rewarding experience when the team worked well and an instructive one when it did not.

3. Mooting is an activity which causes in most students a powerful mixture of elation and terror

Much of the discussion which took place during the focus group interviews was concerned with students' affective responses to mooting. It was clear that it is an activity which stirs up powerful emotions both positive and negative. As it is the latter which was probably the least surprising, the comments which reflected student anxiety about mooting will be examined first. They were along the following lines:

- I found it a stressful experience generally because of time constraints because quite often the majority of my work was left to do in about 2-3 days. My main recollection from mooting is a really concentrated period of stressful times;

- I think the fear thing actually played a really large part because you had to know it just in case they asked about it so you went through it as thoroughly as possible;

- I've had two migraines in my life and one of them was when I was in the Banco court. I couldn't even hardly open my eyes, but we got through it. And that was just stress.

However, most students were keen to point out that despite, or maybe because of, this incredible amount of stress, there were rewards also:

- But it's a very stressful exercise, but very worthwhile. I think that after having done four we are a lot less stressed now than we were in the very beginning;

- I think it was a fifty-fifty fear plus interest thing because I was interested, but I think I was interested because I was really scared and I really wanted to do well. I had high expectations of myself, but fear made me prepare more than I would have for an exam.

This attitude was actually carried a lot further in many of the comments which indicated that many students actually like to moot. The following extracts are even more fascinating when one tries to think of any other pieces of assessment in legal education which would elicit a similar response:

- It's not like handing in an assignment and saying "Well, that is it". You came out and went "Wow." You'd accomplished something ... And when you do an exam its sort of like, "Oh well, done now. Nothing I can do about it. No sense worrying." But this was like 'I did something here."

- It's just a relief just getting out of there - also there's a sort of a feeling: "Wow, that's my first case. If that's what I have got ahead of me... I liked that, I enjoyed that. I like the Courts - it sort of confirms you in the part of a lawyer; ${ }^{62}$

- I guess I am still fired up after the moot and often will be for hours and often will sit down and talk to my partner about how it went and go back over the arguments. I don't know, I left one time thinking you know we are getting towards, thinking about becoming lawyers and this to me was part of the realisation that yes, we were able to carry through on the research, the delivery, and any opposition we had to ... whatever case we were trying to argue. And often you'd be arguing a case that you maybe felt was a loser to begin with and you had to develop arguments to try to either minimise the loss, or damage, or to actually start to believe in your argument towards the end and as a result was able to convince the mootmaster. So yes, I guess that realisation that this is development and we have done better each time that we have gone into a moot situation and that we will be well prepared when we do get out into the real world. If we get into this situation, we at least will not freeze because of the role play we have gone through we will have the necessary tools to be able to survive;

- I think there's the odd person who perhaps is so daunted by the experience that they never overcome that, but I think for the majority of us it's an empowering sort of situation, because even though I have always gone to moot with the most ridiculous argument you come out feeling - my God at least you can answer questions and feel that you can make, sort of some reasonable argument with the basic material 
you have. I really enjoy moots because I enjoy the public speaking aspect of having to get up and face the person on the other side and present some sort of sequential argument. It's a challenge. Yes, a personal challenge.

- Now that I know what it is like, I can do it better. I left feeling really empowered by the experience for the next time.

Empowerment? Accomplishment? Confirmation of vocation? Can this really be a piece of assessment which students spend most of their time dreading at Law School? It seems ironic that so much is made about the anxiety involved - one student recounted stories of colleagues being physically sick with terror - yet the self-confidence which students gain is a much better kept secret. The students were specifically asked whether they felt similarly about other items of assessment, and despite feelings of relief when exams or assignments were completed, it seems nothing comes close to moots in the range of emotions induced. Exams may terrify but there is still the saving grace of anonymity, which the oral presentation required by moots does not afford students.

Interestingly, many students thought the moots were "such a big deal" due to the formalities which they were required to adhere to. Going to the courts was a big part of this for all students. Those who had done it felt it had added an edge to the experience, whilst when it was suggested to the first years that they could just as easily continue to moot in the University moot court, the reaction was summed up by the following statement:

You really wouldn't feel like you were going anywhere or accomplishing something. It'd just be the same thing over and over again. It's good to go a step up the ladder. Another factor which had a huge impact was the formal attire which students adopted for the purposes of their moot. This is illustrated neatly by the following exchange amongst first year students:

Yeah, that was a different part of it — getting dressed up for it really made it a more appropriate situation. Like if you had just turned up in your normal uni clothes, it would just be like doing another oral [presentation].

It put you into character.

Yeah, that was good.

When you say "into character” do you mean... which character?

A professional character.

Being professional — knowing your stuff. It sort of reinforces the fact, hey look at me — I know what I'm doing, I know what I'm doing.

It was something else that gave you confidence.

Apart from fear and stress, the only thing tarnishing this seemingly enriching experience was that several students thought that the actual moot was over quite quickly and was inadequately weighted given that you had been "eating, sleeping, drinking, breathing moot" for so long. This may be something subject convenors may wish to consider, especially in light of the above comments. Students are enjoying this piece of assessment and are deriving great personal advantage from it. Additionally, it involves a lot of time which academics could spend elsewhere. Surely then, it is to everyone's benefit to weight it more heavily so that all parties feel that it is worth the effort from an assessment point of view as well as a learning one?

\section{Mooting is an excellent way to learn the substantive law}

Perhaps this fourth element of mooting is the most exciting and also the most important. Much of the discussion which occurred in the course of the focus group interviews centred on the power of moots as a learning experience. Some of this has been referred to obliquely in the foregoing sections, but there was also a definite theme present that in contrast to many other forms of assessment, mooting encourages students to adopt a deep or achieving learning approach. This is borne out by comments such as:

- In a way, I sort of think it was more of a test than an exam because it wasn't like memorising stuff. You had to know it and you had to be able to talk about it under a lot of different situations. You had to really know what you are on about. You had to be familiar with it, more so than in an exam where you can just 
spout things off;

- I think mooting makes you understand the work a lot more than assignments or some areas of assignments. You really are not sure what is going on, you really get the information and just put it down but you don't really have to understand it. But with mooting, since you will be asked questions on it, you really have to know exactly what you are talking about before you get up;

- You have to know your facts - you have to know everything - and it wasn't like superficial knowledge. You have to understand why - there was some level of understanding that you needed to get through it.

However, while there is very little written on the learning benefit of mooting, it is one clearly appreciated by students. Brown recognised that students who took part in the Jessup Mooting Competition on the basis of their interest in mooting, soon became "fascinated with international law as a subject of study”. ${ }^{33}$ Gaubatz was more revealing when he wrote:

In moot court problems, cases and their use have a significance sometimes unexpressed in the classroom. The limits imposed by procedural status, the use of obiter dictum and ratio decidendi, and reasoning by analogy, all take on new meaning when the student must try to use the case in support of his client's position or to distinguish a case against him. By illumination, moot court can materially assist the educational process. It can clarify concepts commonly used in the classroom, and in effect can provide a tutorial for legal education. ${ }^{65}$

Generally though, this result from the interviews accords with Jackling’s argument that the integration of academic study and practical training enhances and reinforces theoretical learning. ${ }^{65}$

This feature of mooting was often referred to as the way it "focuses my mind", and this raises a subissue, in that moots themselves are fairly limited in the area with which they deal. Students did not have a major problem with this but it was clear that although they often expressed a desire for more moots in their degree, they acknowledged that there would be an awful lot of law which they would not be assessed on and thus not know. This is summed up in the following phrase:

I find they give me a good knowledge of a very narrow area of law, obviously, a particular issue, within a particular area of law - which I don't imagine would prepare me terribly well except some knowledge of the law per se. But certainly process is good there, so I enjoy them for that part, but if I want to get broader knowledge or broader appreciation of a given area of law, then a more generalised assignment is perhaps better.

Concluding this section, it is worth noting that, in accordance with the feelings of extreme confidence students mentioned above, mooting also stimulates their interest and enthusiasm for the substantive law. This obviously owes a lot to the way they are required to approach the law in the case of a moot, but should also be cross-referenced with the theory section of this paper. The motivational aspect of situated learning through constructivism and experiential learning is highly relevant here. Students have control over their own learning and this is the result:

- But the other thing too is that you really feel satisfied that you know the work - at the time. Like you forget everything afterward, like I can't remember what I said but it's probably one of the only times that I do an assessment that I would be happy to turn around to someone and give them advice on how I think the law stands;

- It's really good that possibly the day before the moot you may be talking to possibly the people you are mooting with or someone who is doing the same topic. You don't have books in front of you and you talk about the issues, you talk about the law, you talk about sections, cases - you never sound so knowledgable as when you go to moot;

- It was good in that it gave you the opportunity to actually talk about the law. Like, it is fine to sort of read it and rewrite it, regurgitate it basically. But to actually get a chance to speak about it on such a... I don't know ... exciting level, as well. It's sort of, you know, glorifying it.

\section{CONCLUSION: MOOTS AS ASSESSMENT}

Of course, moots are just one of the many items of assessment which can be presented to students at Law School. There are two purposes of assessment - summative and formative. Summative assessment is concerned with certifying that the student has achieved a certain level, so that $\mathrm{s} / \mathrm{he}$ may be presented to the world as possessing certain knowledge. Formative assessment focuses much more on the student, rather than the external world. It is assessment for learning. "Students engage in the problems and discourse of a 
given area and are given encouragement, response and feedback on what they do, as appropriate, with a view to them becoming more effective in their learning." 66

Moots as part of the undergraduate law degree seem to have less of a summative purpose than they did at the time of their use in the Inns of Court many centuries ago. Under that system, moots were really the sole device whereby barristers received formal acknowledgment in their profession. With the rise of law as an academic discipline and emphasis being placed on the attainment of a degree, determined by the all important Grade Point Average (GPA), this qualifying function has lessened considerably, though clearly marks awarded for moots serve to make up the student's degree. ${ }^{67}$

However, moots did not only serve a summative function at the Inns of Court. They literally were the legal education of those who sought to become lawyers. In this regard, they served a formative purpose which was equal, if not more so, to their importance as providing a yardstick for formal qualification. Moots are formative in that they require students to develop and strengthen their own knowledge of an area of the law, and legal processes and concepts generally, and provide incentive to learn. The qualitative data above demonstrates that students view moots primarily as having a formative function. They encourage students to immerse themselves in an area of the substantive law, work closely with their peers and develop several important practical skills. That was the focus of almost all students. They did not so much talk about moots as testing them, but rather as focussing them in their learning.

Rowntree identifies six separate purposes of assessment, which are related to the summative or formative perspectives. Of those which are not "administrative and go chiefly to people outside the immediate teacher-student relationship”, he includes student motivation, feedback to students and teachers, and preparation for life. ${ }^{68}$ The issue of moots and motivation needs little comment, following, as it does, students' own remarks. Rowntree states that "the line between coercion and encouragement is hard to draw", ${ }^{69}$ and certainly this is true of mooting. Students recounted feelings of tremendous fear yet also enormous interest and enthusiasm. Are we coercing or encouraging them? It seems mooting is an example of assessment which does both at a high level.

It is fairly easy to appreciate that moots provide a concrete experience, but questions must be asked as to whether legal educators have been seriously encouraging the next step in Kolb’s Experiential Cycle reflective observation. Most of the students interviewed were critical of the amount of feedback they received on their performance in moots. In a number of institutions, it seems it is not uncommon for mooters merely to receive a numerical rating with the invitation to arrange to speak privately with the academic involved, should they desire more feedback. Given that many students will be reluctant to do so and will just let the matter drop, are we really depriving students of feedback which would enable them to learn from - and improve upon - their experience? Certainly students can reflect on their experience individually and with their peers, yet if they are to engage in a truly meaningful experiential cycle of learning, it will be helpful to know what they did well and not so well in the eyes of the assessor. A few students may be lucky enough to gain such feedback informally but such an ad hoc approach scarcely seems satisfactory given the amount of effort the exercise requires.

Following Gibbs' suggestion, it may be that lecturers should conduct a structured de-briefing session in order to analyse the moot with the students, and thus enable them to engage in critical self-reflection. ${ }^{70}$ Boud, Keogh and Walker expand on this theme in their book Reflection: Turning Experience into Learning $^{71}$ and have designed a three stage model illustrating the components of meaningful reflection. Academics should be conscious of their role in facilitating student reflection — just because it is called selfreflection does not mean that students can do it without sufficient feedback from their teachers.

Ramsden says:

Assessment methods that are perceived to test the ability to reproduce accurately large quantities of information presented in class, or to manipulate procedures unthinkingly, tell students that our fine aims for conceptual understanding are but a veneer on the solid material of recalling facts. ${ }^{72}$

Moots do not fall within this description of a poor or inappropriate assessment technique. A theoretical understanding of their nature should make this evident to us, but the opinions and reactions of students confirms that they do not see moots as something for which they can memorise material without understanding it. The phrase "eating, sleeping, drinking, breathing moot" shows how absorbed in the task students can become. Obviously, it can be stated that moots engage students in a learning process which is 
not often seen in response to many other forms of assessment. They clearly find it an educationally enriching process, and this can be ensured by the provision of at least a basic level of feedback.

As we have seen, the use of mooting varies between Law Schools and that situation will continue. There are advantages in all three of the approaches examined in this paper, and all of them go some way toward making mooting an educational experience which is unique. Hopefully though, an increased understanding of which educational theories are in operation when mooting occurs and what mooting actually means to students, will lead to the continued, and perhaps increased, use of moots in the legal education of undergraduates, in the manner most appropriate to the circumstances of each Law School.

* Associate Lecturer, Faculty of Law, University of Western Sydney, Macarthur. The author gratefully acknowledges the support and advice of both Lyndal Taylor and Mary Keyes. The four anonymous referees are also thanked for their helpful suggestions. The author alone remains responsible for the contents of this paper.

(C) 1996. (1996) 7 Legal Educ Rev, 67.

2 Women were not admitted to the Inns.

3 Prest compares the education provided by the Inns to that offered by the two universities, Oxford and Cambridge: "The essence of the inns' exercises was the formulation and debate of a hypothetical case or set of circumstances involving one or more controversial questions of law; just as in disputation the university undergraduate maintained a thesis by argument from philosophical and theological authorities, so in 'case-putting', bolts and moots, the inns of court student sought to justify his interpretation of the law by citing the maxims, precedents and principles which were the authorities of his craft.” (WR Prest, The Inns of Court under Elizabeth 1 and the Early Stuarts 1590-1640 (London: Longman, 1972) 116.

4 C Warren, A History of the American Bar (Buffalo: Hein \& Co., 1990) 29.

5 W Holdsworth, Some Makers of English Law — The Tagore Lectures 1937-38 reprint ed (Buffalo: Hein \& Co., 1983 ) 49.

6 That is sat as an inner barrister and recited the pleadings.

7 Lord Hailsham ed, Halsbury's Laws of England 4th ed (London: Butterworths, 1973) vol 3, Title: Barristers, at para 1102.

8 This general term is used because it is clear that lawyers were all educated in this way for many years before the profession split into two branches, which Warren dates at about 1556. Warren, supra note 4, at 28.

9 For an interesting discussion on the development of universities in legal education, see D Sugarman, Legal Theory, the Common Law Mind and the Making of the Textbook Tradition, in W Twining ed, Legal Theory and Common Law (Oxford: Basil Blackwell, 1986) 29-33.

10 M Le Brun, \& R Johnstone, The Quiet (R)evolution — Improving Student Learning in Law (Sydney: Law Book Company, 1994) 307.

11 JT Gaubatz, Moot Court in the Modern Law School (1981) 31 J Legal Educ 87 at 90-96.

12 Le Brun, \& Johnstone, supra note 10, at 308.

13 Mock trials seem to be more commonly used in Business Law courses and two interesting examples of this are described by C $\mathrm{J}$ Miller, Mock Jury Trial: A Model for Business Law I Courses (1987) 6 J Legal Stud Educ 91; and AG Schaefer, Mock Trials: A Valuable Teaching Tool (1989/90) 8 J Legal Stud Educ 199.

14 Le Brun, \& Johnstone, supra note 10, at 309.

15 The author wishes to thank the staff of the Law Faculties of Griffith University, the Queensland University of Technology and the University of Queensland for their assistance in providing information relevant to this section of the paper.

16 It should be noted that the moots programme at QUT has just been reviewed by a Working Party of the Undergraduate Law Curriculum Committee. The recommendation was made that the current system of mooting should be retained, but with several strategies suggested to increase students' opportunities to moot. However, moots remain an optional form of assessment within specified units.

17 It is presumably for this reason that the majority of UQ moots ask students to argue an appeal from an actual decision handed down by a real court.

18 The Moot Guides of both QUT and UQ are evidence of this.

19 This shall be developed later, in the context of the qualitative research.

20 J Biggs, What do inventories of students' learning processes really measure? A theoretical review and clarification (1993) $63 \mathrm{~J}$ Brit Educational Psychology 3.

21 "When the term 'strategy' is imported from cognitive psychology, what really is meant is a tactic, a procedure, for handling a set task". Id at 6.

22 BS Bloom, Taxonomy of Educational Objectives: The Classification of Educational Goals - Handbook 1, The Cognitive Domain (New York: Longmans, Green \& Co., 1956).

23 J Biggs, supra note 20, at 7.

24 P Ramsden, Learning to Teach in Higher Education (London: Routledge, 1992) 41-44.

25 Id at 44. Derek Rowntree fuses all aspects of Blooms' Taxonomy by saying that even "the Ph.D. student cannot write his thesis (however cognitive) without having both a commitment (affective) to the value of what he is doing and the ability (psychomotor) to type or write by hand.” D Rowntree, Assessing Students: How shall we know them? (London: Kogan Page Ltd., 1987 ) 95.

26 J Biggs, supra note 20, at 10. Petter writes that law curricula traditionally are "reluctant to include affective learning objectives", and so moots are an exception in that they do tend to take account of the affective domain, whilst still looking at the cognitive. A Petter, A Closet Within the House: Learning Objectives and the Law School Curriculum, in N Gold ed, Essays on Legal Education (Toronto: Butterworths, 1982) 95.

27 In reality it is more commonly a case of collusion between the mooters than prediction. This, however, involves probably more strategies as the mooters negotiate with each other and decide how much of their case to reveal to the opposing side.

28 S Bobbitt Nolen, Reasons for Studying: Motivational Orientations and Study Strategies (1988) 5(4) Cognition \& Instruction 269 at 272.

29 J Biggs, Introduction and Overview, in J Biggs ed, Teaching for Learning - The View from Cognitive Psychology (Victoria: 
ACER, 1991) 2; though Candy prefers to explain it by saying there "is not a single monolithic theory, but rather a cluster of perspectives united by underlying similarities in worldview.” P Candy, Self-Direction for Lifelong Learning (San Francisco: Jossey-Bass Publishers, 1991) 252.

30 Biggs, supra note 29.

31 R Säljö, Learning in the Learner's Perspective II: Differences in Awareness - Report of the Institute of Education, No.77 (Sweden: University of Goteborg, 1979) quoted in G Gibbs et al, A Review of the Research of Ference Marton and the Goteburg Group: A Phenomenological research Perspective on Learning (1982) 11 Higher Educ 123 at 134.

32 Säljö, supra note 31.

33 LB Resnick, Introduction, in LB Resnick ed, Knowing, Learning and Instruction: Essays in Honour of Robert Glaser (Hillsdale, New Jersey: Lawrence Erlbaum Associates, 1989) 1.

34 Le Brun, \& Johnstone, supra note 10, at 72.

35 JS Brown, A Collins, \& P Dugid, Situated Cognition and the Culture of Learning (1989) (Jan-Feb) Educ Researcher 32 at 34.

36 For general characteristics of lawyers which the Queensland legal profession is looking for, see JK de Groot, Producing a Competent Lawyer - Alternatives Available (Sydney: Centre for Legal Education, 1995) 130.

37 DA Kolb, Experiential Learning: Experience as The Source of Learning and Development (New Jersey: Prentice-Hall Inc, 1984) 21.

38 G Gibbs, Learning by Doing — A Guide to Teaching and Learning Methods (London: Further Education Unit, 1988$) 55$.

39 For a generic view of roleplays see Gibbs, supra note 38, at 58-61.

40 L Andresen, D Boud, \& R Cohen, Experience-Based Learning, in G Foley ed, Understanding Adult Education and Training (Sydney: Allen \& Unwin, 1995) 207.

41 Id at 207.

42 K Winsor, Introduction to Materials for Students — Problem-based Learning Segment, unpublished paper (Sydney: College of Law) quoted in K Winsor, Toe in the Bathwater: Testing the Temperature with Problem-based Learning (1989) 7(1) J Professional Legal Educ 1 at 2.

43 R Cowdroy, Concepts, Constructs and Insights: The Essence of Problem-Based Learning in Chen et a1, ed, Reflections on Problem Based Learning (Sydney: Australian Problem-Based Learning Network, 1994) 48.

44 D Laurillard, Implications of research for the design of problem-solving tasks, quoted in JA Bowden ed, Student learning: research into practice - the Marysville Symposium (Melbourne: Centre for the Study of Higher Education, University of Melbourne, 1986).

45 Of course, there is now a wealth of literature on this topic, but a good place to start is P Ramsden, Learning to Teach in Higher Education (London: Routledge, 1992) ch 4.

46 Laurillard, supra note 44, at 171.

47 D Watkins, \& M Regmi, An Investigation of the Approach to Learning of Nepalese Tertiary Students (1990) 20 Higher Educ 459.

48 The realities of group work in a PBL situation are discussed succinctly by M Conrick, Problem Based Learning — Managing Students Transitions, in Chen, supra note 43, at 244-47.

49 C Marshall, \& GB Rossman, Designing Qualitative Research (California: Sage Publications, 1989) 78.

50 M Quinn Patton, Qualitative Evaluation and Research Methods 2nd ed (Newbury Park: Sage Publications, 1990$) 13$.

51 R Tesch, Qualitative Research - Analysis Types \& Software Tools (New York: The Falmer Press, 1990) 2.

52 See for example, RA Krueger, Focus Groups — A Practical Guide for Applied Research (California: Sage Publications, 1988); and DW Stewart, \& PN Shamdasani, Focus Groups — Theory and Practice (California: Sage Publications, 1990).

53 F Marton, Phenomenography: Exploring Different Conceptions of Reality, in DM Fetterman ed, Qualitative Approaches to Evaluation in Education (New York: Praeger, 1988) 179.

54 Tesch, supra note 51, at 65.

55 AL Russell, The Synergetic Focus Group Discussion as Data for Phenomenographic Research, unpublished manuscript, School of Language and Literacy Education, Queensland University of Technology, September 1993.

56 C Edelsky, Who's Got the Floor? (1981) 10 Language Soc'y 383.

57 Tesch, supra note 51, at 92.

58 L Svensson, Theoretical Foundations of Phenomenography, paper presented at Phenomenography: Philosophy and Practice Conference, QUT, Brisbane, November 1994

59 This may have something to do with the fact that all Griffith University Law students must also be studying another degree, the two being integrated. The aim of the Law School is to "create a law degree that not only provides the academic stage of a professional lawyer's education but also an education that is of use in the many other purposes to which law degrees are increasingly put." Appendix One: The Griffith Law Curriculum, (1992) 1 Griffith L Rev viii. However, many of the students indicated throughout the course of the interviews that they were intending to practice law professionally, yet they were in accordance on this issue with those students who did not reveal their career intentions.

60 P Anderson, \& I Henley, Problem-Based Learning and the Development of Team Skills in Aviation Studies, in Chen, supra note 43, at 319 .

61 Author's emphasis.

62 This quote also raises a separate but no less interesting issue - that of students' perceptions of law. Whilst students can obviously identify mooting with playing "the part of a lawyer", do they have a similar perception in regard to other work which is actually done by lawyers - including alternative dispute resolution? Are Law Faculties perhaps presenting students with an unbalanced view as to what it entails to practice law - emphasising adversarial, court-based work at the expense of exploring other facets of the legal profession's role?

These two questions clearly relate to the issues discussed in this paper, but would be more appropriately and comprehensively answered in the context of separate research.

63 C Brown, The Jessup Mooting Competition as a Vehicle for Teaching Public International Law, in The Canadian Yearbook of International Law 1978, vol 16, 332 at 335

64 Gaubatz, supra note 11, at 89.

65 N Jackling, Academic and Practical Legal Education: Where Next? (1986) 4 J Prof Legal Educ 1, at 4.

66 D Boud, Assessment and the Promotion of Academic Values (1990) 15(1) Stud Higher Educ 101, at 102. 
67 Though note that moots are a significant feature of Bar Practice Courses for those graduates seeking to qualify for admission to the Bar.

68 See D Rowntree, Assessing Students: How shall we know them? (London: Kogan Page Ltd., 1987) 22-31.

69 Id at 23.

70 See Gibbs, supra note 38, at 46-48 and 61 for a simple model of what this process involves.

71 (London: Kogan Page, 1985) 36.

72 Ramsden, supra note 24, at 72. 